\title{
Predictors for timely initiation of breastfeeding after birth in the hospitals of Nepal- a prospective observational study
}

Rejina Gurung ${ }^{1,2} \mathbb{D}$, Avinash K. Sunny ${ }^{1} \mathbb{D}$, Prajwal Paudel ${ }^{3}$, Pratiksha Bhattarai ${ }^{1}$, Omkar Basnet ${ }^{1} \mathbb{D}$, Srijana Sharma ${ }^{1}$, Durgalaxmi Shrestha ${ }^{4}$, Seema Sharma ${ }^{5}$, Honey Malla ${ }^{1}$, Dela Singh ${ }^{6}$, Sangeeta Mishra ${ }^{3}$ and Ashish KC ${ }^{2,3^{*}}$ (D)

\begin{abstract}
Background: Timely initiation of breastfeeding can reduce neonatal morbidities and mortality. We aimed to study predictors for timely initiation of breastfeeding (within $1 \mathrm{~h}$ of birth) among neonates born in hospitals of Nepal.

Method: A prospective observational study was conducted in four public hospitals between July and October 2018. All women admitted in the hospital for childbirth and who consented were included in the study. An independent researchers observed whether the neonates were placed in skin-to-skin contact, delay cord clamping and timely initiation of breastfeeding. Sociodemographic variables, obstetric and neonate information were extracted from the maternity register. We analysed predictors for timely initiation of breastfeeding with Pearson chisquare test and multivariate logistic regression.
\end{abstract}

Results: Among the 6488 woman-infant pair observed, breastfeeding was timely initiated in $49.5 \%$ neonates. The timely initiation of breastfeeding was found to be higher among neonates who were placed skin-to-skin contact (34.9\% vs $19.9 \%, p$ - value < 0.001). The timely initiation of breastfeeding was higher if the cord clamping was delayed than early cord clamped neonates (44.5\% vs $35.3 \%, p$ - value $<0.001$ ). In multivariate analysis, a mother with no obstetric complication during admission had $57 \%$ higher odds of timely initiation of breastfeeding (aOR $1.57 ; 95 \% \mathrm{Cl} 1.33,1.86)$. Multiparity was associated with less timely initiation of breastfeeding (aOR 1.56; $95 \% \mathrm{Cl} 1.35$, 1.82). Similarly, there was more common practice of timely initiation of breastfeeding among low birthweight neonates (aOR 1.46; 95\% Cl 1.21, 1.76). Neonates who were placed skin-to-skin contact with mother had more than two-fold higher odds of timely breastfeeding (aOR 2.52; $95 \% \mathrm{Cl} 2.19$, 2.89). Likewise, neonates who had their cord intact for 3 min had 37\% higher odds of timely breastfeeding (aOR 1.37; 95\% Cl 1.21, 1.55).

Conclusions: The rate of timely initiation of breastfeeding practice is low in the health facilities of Nepal. Multiparity, no obstetric complication at admission, neonates placed in skin-to-skin contact and delay cord clamping were strong predictors for timely initiation of breastfeeding. Quality improvement intervention can improve skin-to-skin contact, delayed cord clamping and timely initiation of breastfeeding.

Keywords: Predictor, Timely initiation of breastfeeding, Neonate placed skin to skin contact, Delayed cord clamping, Nepal

\footnotetext{
* Correspondence: ashish.k.c@kbh.uu.se

${ }^{2}$ Department of Women's and Children's Health, Uppsala University, Dag

Hammarskjöldsväg 14B, Uppsala, Sweden

${ }^{3}$ Paropakar Maternity and Women's Hospital, Kathmandu, Nepal

Full list of author information is available at the end of the article
}

(c) The Author(s). 2021 Open Access This article is licensed under a Creative Commons Attribution 4.0 International License, which permits use, sharing, adaptation, distribution and reproduction in any medium or format, as long as you give appropriate credit to the original author(s) and the source, provide a link to the Creative Commons licence, and indicate if changes were made. The images or other third party material in this article are included in the article's Creative Commons. licence, unless indicated otherwise in a credit line to the material. If material is not included in the article's Creative Commons licence and your intended use is not permitted by statutory regulation or exceeds the permitted use, you will need to obtain permission directly from the copyright holder. To view a copy of this licence, visit http://creativecommons.org/licenses/by/4.0/ The Creative Commons Public Domain Dedication waiver (http://creativecommons.org/publicdomain/zero/1.0/) applies to the data made available in this article, unless otherwise stated in a credit line to the data. 


\section{Background}

Envisioning a world where every child can survive and thrive requires global commitment to promote and support evidence-based neonatal and child health interventions [1]. Worldwide, the neonatal mortality rate has fallen with a decrease in neonatal sepsis which is a major killer disease [2]. A systematic review has shown that the early initiation of breastfeeding has reduced neonatal mortality due to any cause among all live births by $44 \%$ and mortality among low birthweights by $42 \%$ and infection related mortality by $45 \%$ [3]. The World Health Organization recommends breastfeeding to be initiated within $1 \mathrm{~h}$ of birth and to be provided exclusively till 6 months of age $[4,5]$. Provision of immediate newborn care that encompasses timely initiation of breastfeeding within $1 \mathrm{~h}$ of birth is crucial to accelerate survival [6].

In 2016, only about $55 \%$ of the mothers initiated timely breastfeeding in Nepal [7]. Antenatal visit, obstetric complication and mode of delivery was associated with timely initiation of breastfeeding [8-10]. Women who delivered at home had a higher rate of timely initiation of breastfeeding than those who delivered at health facility [11]. A multi-country health facility-based observation study including Nepal as a site showed that only $10.9 \%$ women timely initiated breastfeeding in health facilities [12]. The neonatal factors such as sex of the neonate, Apgar score and gestational age were associated with timely initiation of breastfeeding [13]. Immediate newborn care practice such as placing baby on mother's chest immediately after the birth had association with timely initiation of breastfeeding [14-16].

In Nepal, efforts have been made to promote breastfeeding in health facilities through implementation of BFHI (Baby Friendly Hospital Initiative) and Community Based Newborn Care Package (CB-NCP) [17, 18]. Considering the coverage of institutional deliveries in Nepal by $60 \%$, timely initiation of breastfeeding is relatively low; raising a concern to scale up the intervention [7]. In this study, we aim to identify predictors for timely initiation of breastfeeding in health facilities in Nepal.

\section{Methods}

\section{Study design and setting}

A prospective observational study was conducted in four public hospitals of Nepal between 1 July 2017 and 17 October 2018 [19]. Koshi Hospital, Bharatpur Hospital, Lumbini Hospital and Western Regional hospital were selected for this particular study.

\section{Study participants}

All pregnant women admitted for vaginal delivery were eligible for the study. Those mothers undergoing caesarean birth, stillbirths and those who did not consent or avail themselves for interview were excluded from the study.

\section{Data collection and management}

Data were collected using paper-based forms through a data surveillance system established in all four hospitals. An eligible pregnant woman admitted to hospital for delivery was enrolled in the study after obtaining her written informed consent. The pregnant woman was then tracked for the observation of intrapartum care received by the mother including immediate newborn care. Twenty-four-hour observation was done by a team of surveillance officers. Sociodemographic, obstetric and newborn's general information were extracted from patient's chart. Both extraction and observation forms were then assessed for completeness by data coordinator placed in each hospital. A weekly surveillance form was filled by the data coordinator. At the end of every week all these filled forms were sent to the central data management office in a sealed envelope. Data were then entered into database by a team of data entry operator using the Census and Survey Processing System (CSPro).

\section{Study variables \\ Obstetric variables}

Parity categorized as nullipara (no previous birth), primipara (one previous birth) and multipara (2-5 previous births) [12]. Obstetric complications at admission were antepartum hemorrhage, hypertensive disorder during pregnancy, premature rupture of membrane, cord prolapse and infection. Mode of birth categorized as spontaneous vaginal and instrumental delivery [12]. Gestational age categorized as < 37 weeks, 37-41 weeks and $\geq 42$ weeks. Birthweight categorized as $\geq 2500$ and < 2500 g. Early initiation of breastfeeding defined as neonate breastfed within $1 \mathrm{~h}$ of birth [12]. Delayed cord clamping defined as cord clamped at 3 min or more. Immediate skin to skin contact defined as neonates placed skin to skin contact with mother soon after birth [12].

\section{Outcome variables}

Timely initiation of breastfeeding was defined as the proportion of neonates who were breastfed within the first hour of birth.

\section{Statistical analysis}

Data were exported into Statistical Package for Social Sciences (SPSS) version 23 for analysis. Pearson chisquare test was used to find out the association between various variables with timely breastfeeding initiation and multiple logistic regression was used to analyze the adjusted odds of the association. At 95\% Confidence Interval, $p$ - value $<0.05$ was considered to be statistically 
significant. Missing data were excluded from the analyses.

\section{Results}

During the study period, total of 6488 mothers were observed for breastfeeding, among whom $49.5 \%$ of them had timely breastfeeding (Fig. 1). During the study period, $27.3 \%$ of neonates were placed skin-to-skin contact with mother soon after birth and 39.5\% of neonates had delay cord clamping (Table 1).

The timely initiation of breastfeeding was higher among women who had one previous birth compared to women who didn't have $(37.8 \%$ vs $28.8 \%, p$ - value < $0.001)$. The practice was more common among women with no obstetric complication at the time of admission $(88.7 \%$ vs $11.3 \%, p$ - value $<0.001)$. Timely initiation of breastfeeding was high among babies who were placed in skin to skin contact $(34.9 \%, p$ - value $<0.001)$. There was higher coverage of timely initiation of breastfeeding in delay cord clamped neonates than in early clamped ( $35.3 \%$ vs $44.5 \%, p$ - value $<0.001$ ) (Table 2 ).

In bi-variate logistic regression, multiparous mothers had higher odds for timely initiation of breastfeeding (cOR 1.44; 95\% CI 1.28, 1.62) when compared to nulliparous women. A Mother with no obstetric complication at the time of admission had two-fold odds of timely initiation of breastfeeding (cOR 2.04; 95\% CI 1.77, 2.35). Neonates when placed skin to skin contact with the mother soon after birth had more than twice-fold higher odds of timely breastfeeding (cOR 2.15; 95\% CI 1.92, 2.41). Delayed cord clamped neonates had higher odds of $47 \%$ of timely initiation of breastfeeding compared to early cord clamped (cOR 1.47; 95\% CI 1.31, 1.64) (Table 2).

In the multivariate logistic regression, multiparous mothers had $56 \%$ higher odds of timely initiation of breastfeeding (aOR 1.56; 95\% CI 1.35, 1.82). Women with no obstetric complication at the time of admission had 57\% increased odds of timely initiation of breastfeeding (aOR 1.57; 95\% CI 1.33, 1.86). Neonates born after a gestational age of less than 37 weeks had 19\% lower odds of timely initiation of breastfeeding (aOR $0.81 ; 95 \%$ CI $0.66,0.98$ ) when compared to neonates born 37 weeks or more. Forty-six percent higher odds of timely initiation of breastfeeding were found among birthweight less than $2500 \mathrm{~g}$ neonates (aOR 1.46; 95\% CI $1.21,1.76)$. Neonates when placed skin-to-skin with mother soon after birth had 2.5-fold odds of timely initiation of breastfeeding (aOR 2.52; 95\% CI 2.19, 2.89). Neonates who had a delay cord clamped had $37 \%$ higher odds of timely initiation of breastfeeding (aOR 1.37; 95\% CI 1.21, 1.55) (Table 3).

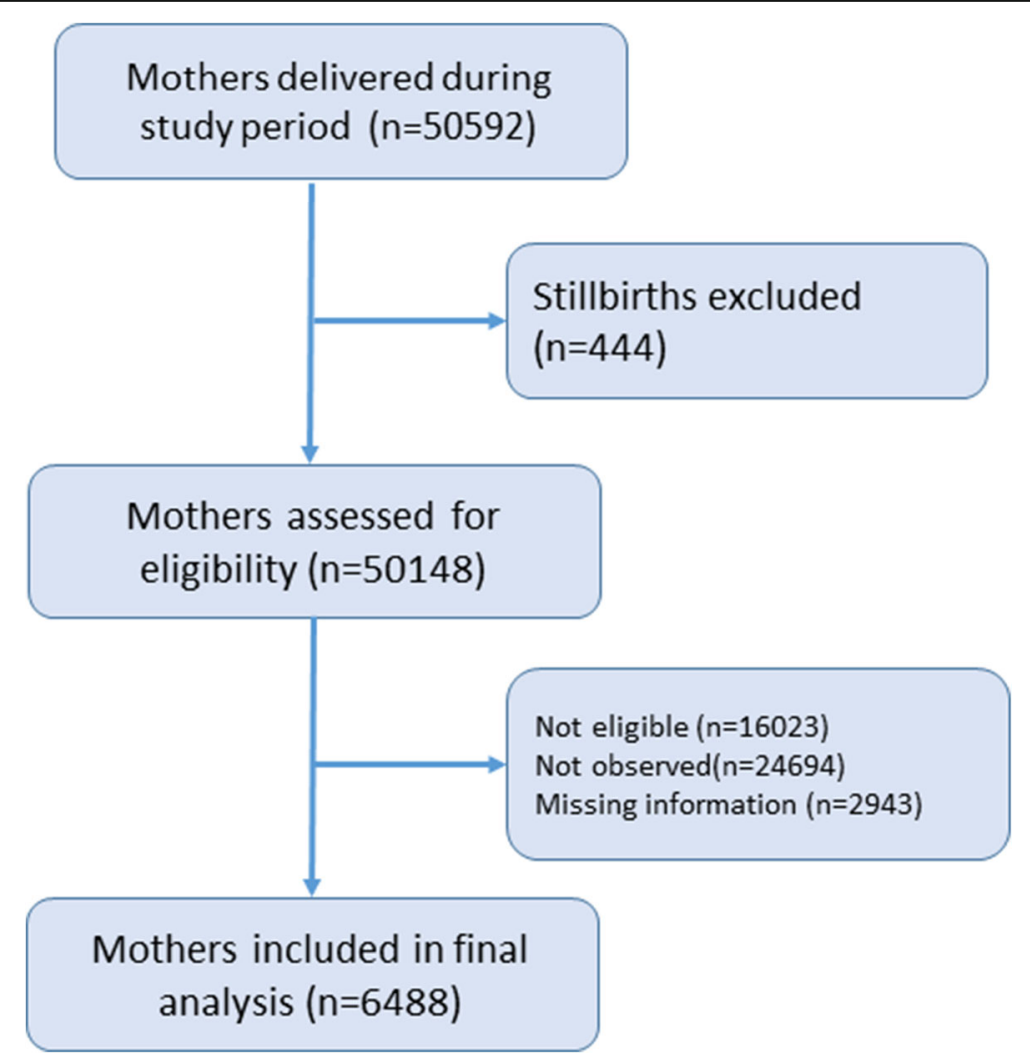

Fig. 1 Study flow diagram 
Table 1 Hospital wise coverage of timely initiation of breastfeeding, neonates placed immediately in skin to skin contact with mother and delayed cord clamping $(n=6488)$

\begin{tabular}{|c|c|c|c|c|c|c|}
\hline \multirow[t]{2}{*}{ Hospitals } & \multicolumn{2}{|c|}{$\begin{array}{l}\text { Timely initiation of } \\
\text { breastfeeding }\end{array}$} & \multicolumn{2}{|c|}{$\begin{array}{l}\text { Neonates placed immediately in skin to skin contact } \\
\text { with mother }\end{array}$} & \multicolumn{2}{|c|}{ Delayed cord clamping } \\
\hline & $\bar{N}$ & $\begin{array}{l}\% \\
(95 \% \mathrm{Cl})\end{array}$ & $\bar{N}$ & $\begin{array}{l}\text { \% } \\
(95 \% \mathrm{Cl})\end{array}$ & $\bar{N}$ & $\begin{array}{l}\% \\
(95 \% \mathrm{Cl})\end{array}$ \\
\hline Western Regional Hospital & $2358 / 3917$ & $60.2(58.7,61.7)$ & $329 / 3913$ & $8.4(7.5,9.3)$ & $1156 / 2671$ & $43.3(41.4,45.2)$ \\
\hline Bharatpur Hospital & $64 / 752$ & $8.5(6.5,10.5)$ & $124 / 752$ & $16.5(13.8,19.1)$ & $196 / 741$ & $26.5(23.3,29.6)$ \\
\hline Koshi Hospital & $6 / 450$ & $1.3(0.3,2.4)$ & $38 / 450$ & $8.4(5.9,11.0)$ & $54 / 448$ & $12.1(9.0,15.1)$ \\
\hline Lumbini Hospital & $782 / 1369$ & $57.1(54.5,59.7)$ & $1282 / 1369$ & $93.6(92.4,94.9)$ & $656 / 1354$ & $48.4(45.8,51.1)$ \\
\hline Total & $3210 / 6488$ & $49.5(48.3,50.7)$ & $1773 / 6484$ & $27.3(26.3,28.4)$ & $2062 / 5214$ & $39.5(38.2,40.9)$ \\
\hline
\end{tabular}

\section{Discussion}

About half of women initiated timely breastfeeding. Multiparity, no obstetric complication at admission, neonates placed in skin-to-skin contact soon after birth and delay cord clamping were strong predictors for timely initiation of breastfeeding.
Delayed cord clamping, a significant predictor for timely initiation of breastfeeding [20], has immediate better physiological outcomes and long-term behavioral outcomes [21]. Improved physiologic stability and alertness immediately after birth could provide major support to successful timely initiation of breastfeeding.

Table 2 Coverage of timely initiation of breastfeeding ( $n=6488$ )

\begin{tabular}{|c|c|c|c|c|c|}
\hline \multirow[t]{2}{*}{ Variables } & \multicolumn{3}{|c|}{ Timely initiation of breastfeeding } & \multirow{2}{*}{$\begin{array}{l}p \text { - } \\
\text { value }\end{array}$} & \multirow[t]{2}{*}{ cOR $(95 \% \mathrm{Cl})$} \\
\hline & No & Yes & Total & & \\
\hline Parity & & & & $<0.001$ & \\
\hline 1 previous birth & 1359 (41.5\%) & $1214(37.8 \%)$ & $2573(39.7 \%)$ & & Ref \\
\hline 0 previous birth & $1084(33.1 \%)$ & $923(28.8 \%)$ & 2007 (30.9\%) & & $0.95(0.85,1.07)$ \\
\hline 2 or more previous births & $835(25.5 \%)$ & $1072(33.4 \%)$ & 1907 (29.4\%) & & $1.44(1.28,1.62)$ \\
\hline Obstetric Complication & & & & $<0.001$ & \\
\hline Yes & $643(20.6 \%)$ & $346(11.3 \%)$ & $989(16.0 \%)$ & & Ref \\
\hline No & $2483(79.4 \%)$ & $2721(88.7 \%)$ & $5204(84.0 \%)$ & & $2.04(1.77,2.35)$ \\
\hline Mode of delivery & & & & 0.34 & \\
\hline Spontaneous vaginal delivery & $3163(96.5 \%)$ & $3083(96.0 \%)$ & $6246(96.3 \%)$ & & Ref \\
\hline Instrumental delivery & $115(3.5 \%)$ & $127(4.0 \%)$ & $242(3.7 \%)$ & & $1.13(0.88,1.47)$ \\
\hline Gestational age & $38.4 \pm 2.2$ & $38.5 \pm 2.2$ & $38.4 \pm 2.2$ & 0.11 & \\
\hline 37-41 week & $2558(79.4 \%)$ & $2324(81.1 \%)$ & $4882(80.2 \%)$ & & Ref \\
\hline$<37$ week & $580(18.0 \%)$ & $487(17.0 \%)$ & $1067(17.5 \%)$ & & $0.92(0.81,1.06)$ \\
\hline$\geq 42$ week & $82(2.5 \%)$ & $54(1.9 \%)$ & $136(2.2 \%)$ & & $0.73(0.51,1.03)$ \\
\hline Birthweight & $2887.8 \pm 486.4$ & $2883.0 \pm 516.4$ & $2885.5 \pm 500.7$ & 0.29 & \\
\hline $2500-4000 \mathrm{~g}$ & $2603(80.8 \%)$ & $2277(79.5 \%)$ & $4880(80.2 \%)$ & & Ref \\
\hline$<2500 \mathrm{~g}$ & $574(17.8 \%)$ & $554(19.3 \%)$ & $1128(18.5 \%)$ & & $1.10(0.97,1.26)$ \\
\hline$\geq 4000 \mathrm{~g}$ & $43(1.3 \%)$ & $34(1.2 \%)$ & $77(1.3 \%)$ & & $0.90(0.57,1.42)$ \\
\hline Newborn placed immediately in skin to skin contact with mother & & & & $<0.001$ & \\
\hline No & $2621(80.1 \%)$ & $2090(65.1 \%)$ & $4711(72.7 \%)$ & & Ref \\
\hline Yes & $653(19.9 \%)$ & 1120 (34.9\%) & $1773(27.3 \%)$ & & $2.15(1.92,2.41)$ \\
\hline Timing of cord clamping & & & & $<0.001$ & \\
\hline Early (<3 min) & 1825 (64.7\%) & $1327(55.5 \%)$ & 3152 (60.5\%) & & Ref \\
\hline Delayed ( $\geq 3 \mathrm{~min}$ ) & 997 (35.3\%) & 1065 (44.5\%) & 2062 (39.5\%) & & $1.47(1.31,1.64)$ \\
\hline
\end{tabular}

COR Crude Odds Ratio 
Table 3 Multivariate analysis of factors associated with timely initiation of breastfeeding

\begin{tabular}{|c|c|c|c|}
\hline Predictors & $p$-value & B-coefficient & aOR $(95 \% \mathrm{Cl})$ \\
\hline \multicolumn{4}{|l|}{ Parity } \\
\hline 1 previous birth & & & Ref \\
\hline 0 previous birth & $<0.001$ & -0.29 & $0.75(0.65,0.87)$ \\
\hline 2 or more previous births & $<0.001$ & 0.45 & $1.56(1.35,1.82)$ \\
\hline \multicolumn{4}{|l|}{ Obstetric complication } \\
\hline Yes & & & Ref \\
\hline No & $<0.001$ & 0.45 & $1.57(1.33,1.86)$ \\
\hline \multicolumn{4}{|l|}{ Mode of delivery } \\
\hline Spontaneous vaginal delivery & & & Ref \\
\hline Instrumental delivery & 0.47 & 0.11 & $1.12(0.82,1.53)$ \\
\hline \multicolumn{4}{|l|}{ Gestational age } \\
\hline 37-41 week & & & Ref \\
\hline$<37$ week & 0.03 & -0.22 & $0.81(0.66,0.98)$ \\
\hline$\geq 42$ week & 0.36 & -0.19 & $0.83(0.55,1.24)$ \\
\hline \multicolumn{4}{|l|}{ Birthweight } \\
\hline $2500-4000 \mathrm{~g}$ & & & Ref \\
\hline$<2500 \mathrm{~g}$ & $<0.001$ & 0.38 & $1.46(1.21,1.76)$ \\
\hline$\geq 4000 \mathrm{~g}$ & 0.14 & -0.42 & $0.66(0.38,1.14)$ \\
\hline \multicolumn{4}{|c|}{ Neonates placed immediately in skin to skin contact with mother } \\
\hline No & & & Ref \\
\hline Yes & $<0.001$ & 0.92 & $2.52(2.19,2.89)$ \\
\hline \multicolumn{4}{|l|}{ Timing of cord clamping } \\
\hline Early $(<3 \mathrm{~min})$ & & & Ref \\
\hline Delayed ( $\geq 3 \mathrm{~min})$ & $<0.001$ & 0.32 & $1.37(1.21,1.55)$ \\
\hline
\end{tabular}

Positive association was found between neonates placed skin-to-skin contact soon after birth and timely initiation of breastfeeding corresponds to the studies that have recommended skin-to-skin contact as crucial step to timely initiation of breastfeeding [4, 22]. Early maternal-infant attachment evokes psycho-physiological behaviors that may be conducive to fulfill basic biological needs [23]. Robust findings and strong recommendations supporting the benefits of early skin to skin contact on timely initiation of breastfeeding have accelerated scale up of quality improvement programs of maternal and newborn care at both national and global levels [14, 24].

Studies have explored the association of maternal parity with timely initiation of breastfeeding [24-27]. Relatively, we also found that nulliparous mothers are unlikely to initiate timely breastfeeding. This finding is similar to the study done in India, in which the firsttime mothers were more likely to delay breastfeeding [28]. First-time mothers might not be familiar with the practice of keeping neonates skin-to-skin and timely initiation of breastfeeding.
Timely initiation of breastfeeding was significantly higher among mothers with no obstetric complications at the time of admission to the hospital. Women with obstetric complication require additional intrapartum management restricting neonates to be early breastfed [13]. Neonates born to mothers with an intrapartum complication are at high risk of developing sepsis, hypothermia and hypoglycemia and can possibly benefit from receiving their mother's breastmilk early [29]. Neonates born after gestational age less than 37 weeks were found to have lower odds of timely initiation of breastfeeding than the full term neonates. These neonates required additional breathing support and require additional support to timely breastfeeding [30]. Increased timely breastfeeding in low birthweight babies could be due to the reinforcement through quality improvement interventions implemented in these hospitals [31].

A major strength of this study is the direct observation of breastfeeding by well-trained observers using a structured checklist in all four hospitals. 


\section{Limitations}

There are several limitations to the study. First, some of the sociodemographic information such as maternal ethnicity, age and sex of neonates was not available for analysis. Second, this study was done to provide descriptive data on the timely initiation of breastfeeding and its predictors among the hospital born neonates, however, observation was limited to only vaginal births excluding neonates born through cesarean section. All the four hospitals had variation in vaginal birth rate, hence, the findings should not necessarily be generalizable to all the public hospitals of Nepal. Finally, the Hawthorne effect might have influenced the behavior of healthcare provider underestimating the true prevalence than explored, although efforts were made to reduce the possible effects of observation [32, 33].

\section{Conclusions}

Delayed cord clamping and immediate skin to skin contact are strong predictors for timely initiation of breastfeeding. An institutional birth, a breastfeeding support program focusing on nulliparous mothers and those with obstetric complication, can increase the timely initiation of breastfeeding. A pregnant woman needs emotional and physical support throughout pregnancy, childbirth and postnatal period. A confident and happy mother who receives continuous support from the healthcare provider can be successful in timely initiation of breastfeeding. Quality improvement interventions can improve the practice through accountability and leadership. Further research is required to understand the factors associated with timely initiation of breastfeeding practice and develop an effective intervention.

\section{Abbreviations \\ aOR: Adjusted Odds Ratio; CB-NCP: Community Based Newborn Care Package; CSPro: Census and Survey Processing System; LMIC: Low and Middle Income Countries; SPSS: Statistical Package for Social Sciences}

\section{Acknowledgements}

We would like to thank all the data coordinators and surveillance officers, hospital manager, nursing in-charge, all the nurses and support staff working in the sick newborn care units. We thank all the mothers and caregivers of the sick newborns who consented to the study.

\section{Authors' contributions}

RG and AKC conceptualized the study. OB did the data mining of the study data. AKS and PP conducted the analysis. AKS, PP and AKC made the first draft. RG and PB made revision to the first draft. DLS, SS, HM, DS, SS and SM made the second and final revision to the draft. All authors reviewed and provided feedback on the revised version and agreed to the final version.

\section{Funding}

No funding was available for this study. Open Access funding provided by Uppsala University.

\section{Availability of data and materials}

The dataset generated and analysed is not publicly available as it is part of larger quality improvement project but can be made available on reasonable request with a data-sharing agreement.

\section{Declarations}

Ethics approval and consent to participate

The ethical approval for the study was taken from the Ethical Review Board (ERB) of Nepal Health Research Council (reg. no. 26-2017). Written consent was obtained from the participants enrolled in the study. Written informed consent for participation in the study was obtained where participants are children (under 16 years old) from their parent or guardian.

Consent for publication

Not applicable.

\section{Competing interests}

We declare no conflict of interest.

\section{Author details}

'Golden Community, Lalitpur, Nepal. '2Department of Women's and Children's Health, Uppsala University, Dag Hammarskjöldsväg 14B, Uppsala, Sweden. ${ }^{3}$ Paropakar Maternity and Women's Hospital, Kathmandu, Nepal. ${ }^{4}$ Bheri Provincial Hospital, Nepalgunj, Nepal. ${ }^{5}$ Seti Provincial Hospital, Dhangadi, Nepal. ${ }^{6}$ Pokhara Academy of Health Sciences, Pokhara, Nepal.

Received: 23 April 2021 Accepted: 12 October 2021

Published online: 29 October 2021

References

1. World Health Organization, UNICEF. Survive and thrive: transforming care for every small and sick newborn. Geneva: WHO; 2018.

2. World Health Organization, UNICEF, UNFPA, World Bank Group and the United Nations Population Division. Maternal mortality: levels and trends 2000 to 2017. Geneva: World Health Organization; 2019.

3. Debes AK, Kohli A, Walker N, Edmond K, Mullany LC. Time to initiation of breastfeeding and neonatal mortality and morbidity: a systematic review. BMC Public Health. 2013;13(Suppl 3):S19.

4. World Health Organization. Protecting, promoting and supporting breastfeeding in facilities providing maternity and newborn services. Geneva: WHO; 2017

5. World Health Organization. Implementation guidance: protecting promoting and supporting breastfeeding in facilities providing maternity and newborn services: the revised baby-friendly hospital initiative. Geneva: WHO; 2018.

6. Bhutta ZA, Das JK, Bahl R, Lawn JE, Salam RA, Paul VK, et al. Can available interventions end preventable deaths in mothers, newborn babies, and stillbirths, and at what cost? Lancet. 2014;384(9940):347-70. https://doi.org/1 0.1016/S0140-6736(14)60792-3.

7. Ministry of Health and Population, New Era, ICF. Nepal Demographic Health Survey. Kathmandu; 2017.

8. Ali F, Mgongo M, Mamseri R, George JM, Mboya IB, Msuya SE. Prevalence of and factors associated with early initiation of breastfeeding among women with children aged < 24 months in Kilimanjaro region, northern Tanzania: a community-based cross-sectional study. Int Breastfeed J. 2020;15(1):80. https://doi.org/10.1186/s13006-020-00322-8.

9. Gebretsadik GG, Tkuwab H, Berhe K, Mulugeta A, Mohammed H, Gebremariam A. Early initiation of breastfeeding, colostrum avoidance, and their associated factors among mothers with under one year old children in rural pastoralist communities of Afar, Northeast Ethiopia: a cross sectional study. BMC Pregnancy Childbirth. 2020;20:448.

10. Johar N, Mohamad N, Saddki N, Tengku Ismail TA, Sulaiman Z. Factors associated with early breastfeeding initiation among women who underwent cesarean delivery at tertiary hospitals in Kelantan, Malaysia. Korean J Fam Med. 2020;42(2):140-9. https://doi.org/10.4082/kjfm.19.0178.

11. Malqvist M, Pun A, KC A. Essential newborn care after home delivery in Nepal. Scand J Public Health. 2017;45(2):202-7. https://doi.org/10.1177/14 03494816683572.

12. Tahsina T, Hossain AT, Ruysen H, Rahman AE, Day LT, Peven K, et al. Immediate newborn care and breastfeeding: EN-BIRTH multi-country validation study. BMC Pregnancy Childbirth. 2021;21(Suppl 1):237. https:// doi.org/10.1186/s12884-020-03421-W.

13. Lau Y, Tha PH, Ho-Lim SST, Wong LY, Lim PI, Citra Nurfarah BZM, et al. An analysis of the effects of intrapartum factors, neonatal characteristics, and 
skin-to-skin contact on early breastfeeding initiation. Matern Child Nutr. 2018;14(1):e12492. https://doi.org/10.1111/mcn.12492.

14. Singh K, Khan SM, Carvajal-Aguirre L, Brodish P, Amouzou A, Moran A. The importance of skin-to-skin contact for early initiation of breastfeeding in Nigeria and Bangladesh. J Glob Health. 2017;7(2):020505. https://doi.org/10. 7189/jogh.07.020505

15. Moore ER, Anderson GC. Randomized controlled trial of very early motherinfant skin-to-skin contact and breastfeeding status. J Midwifery Womens Health. 2007;52(2):116-25. https://doi.org/10.1016/j.jmwh.2006.12.002.

16. Moore ER, Bergman N, Anderson GC, Medley N. Early skin-to-skin contact for mothers and their healthy newborn infants. Cochrane Database Syst Rev. 2016;11(11):CD003519.

17. Pradhan X, Upreti SR, Kc NP, Thapa K, Shrestha PR, Shedain PR, et al. Fitting community based newborn care package into the health systems of Nepal. J Nepal Health Res Counc. 2011;9(2):119-28.

18. Kc A, Bhandari A, Pradhan YV, Kc NP, Upreti SR, Thapa K, et al. State of maternal, newborn and child health programmes in Nepal: what may a continuum of care model mean for more effective and efficient service delivery? J Nepal Health Res Counc. 2011;9(2):92-100.

19. Kc A, Bergstrom A, Chaulagain D, Brunell O, Ewald U, Gurung A, et al. Scaling up quality improvement intervention for perinatal care in Nepal (NePeriQP); study protocol of a cluster randomised trial. BMJ Glob Health. 2017;2(3):e000497. https://doi.org/10.1136/bmjgh-2017-000497.

20. Nelin V, Kc A, Andersson O, Rana N, Malqvist M. Factors associated with timing of umbilical cord clamping in tertiary hospital of Nepal. BMC Res Notes. 2018;1 1(1):89. https://doi.org/10.1186/s13104-018-3198-8.

21. Hooper SB, Polglase GR, te Pas AB. A physiological approach to the timing of umbilical cord clamping at birth. Arch Dis Child Fetal Neonatal Ed. 2015; 100(4):F355-60. https://doi.org/10.1136/archdischild-2013-305703.

22. Gebremeskel SG, Gebru TT, Gebrehiwot BG, Meles HN, Tafere BB, Gebreslassie GW, et al. Early initiation of breastfeeding and associated factors among mothers of aged less than 12 months children in rural eastern zone, Tigray, Ethiopia: cross-sectional study. BMC Res Notes. 2019; 12(1):671. https://doi.org/10.1186/s13104-019-4718-x.

23. Victora CG, Bahl R, Barros AJ, Franca GV, Horton S, Krasevec J, et al. Breastfeeding in the 21st century: epidemiology, mechanisms, and lifelong effect. Lancet. 2016;387(10017):475-90. https://doi.org/10.1016/S0140-6736(1 5)01024-7.

24. Ndirangu MN, Gatimu SM, Mwinyi HM, Kibiwott DC. Trends and factors associated with early initiation of breastfeeding in Namibia: analysis of the demographic and health surveys 2000-2013. BMC Pregnancy Childbirth. 2018;18(1):171. https://doi.org/10.1186/s12884-018-1811-4.

25. Lyellu HY, Hussein TH, Wandel M, Stray-Pedersen B, Mgongo M, Msuya SE. Prevalence and factors associated with early initiation of breastfeeding among women in Moshi municipal, northern Tanzania. BMC Pregnancy Childbirth. 2020;20(1):285. https://doi.org/10.1186/s12 884-020-02966-0.

26. Taha Z, Ali Hassan A, Wikkeling-Scott L, Papandreou D. Prevalence and associated factors of caesarean section and its impact on early initiation of breastfeeding in Abu Dhabi, United Arab Emirates. Nutrients. 2019;11(11): 2723.

27. Woldeamanuel BT. Trends and factors associated to early initiation of breastfeeding, exclusive breastfeeding and duration of breastfeeding in Ethiopia: evidence from the Ethiopia demographic and health survey 2016. Int Breastfeed J. 2020;15(1):3. https://doi.org/10.1186/s13006-0190248-3.

28. Patel A, Banerjee A, Kaletwad A. Factors associated with prelacteal feeding and timely initiation of breastfeeding in hospital-delivered infants in India. J Hum Lact. 2013;29(4):572-8. https://doi.org/10.1177/0890334412474718.

29. Griffiths LJ, Tate AR, Dezateux C. The contribution of parental and community ethnicity to breastfeeding practices: evidence from the millennium cohort study. Int J Epidemiol. 2005;34(6):1378-86. https://doi. org/10.1093/ije/dyi162

30. Kc A, Lawn JE, Zhou H, Ewald U, Gurung R, Gurung A, et al. Not crying after birth as a predictor of not breathing. Pediatrics. 2020;145(6):e20192719. https://doi.org/10.1542/peds.2019-2719.

31. Kc A, Ewald U, Basnet O, Gurung A, Pyakuryal SN, Jha BK, et al. Effect of a scaled-up neonatal resuscitation quality improvement package on intrapartum-related mortality in Nepal: a stepped-wedge cluster randomized controlled trial. PLoS Med. 2019;16(9):e1002900. https://doi. org/10.1371/journal.pmed.1002900.
32. McCambridge J, Witton J, Elbourne DR. Systematic review of the Hawthorne effect: new concepts are needed to study research participation effects. J Clin Epidemiol. 2014;67(3):267-77. https://doi. org/10.1016/j.jclinepi.2013.08.015.

33. Day LT, Sadeq-Ur Rahman Q, Ehsanur Rahman A, Salim N, Kc A, Ruysen H, et al. Assessment of the validity of the measurement of newborn and maternal health-care coverage in hospitals (EN-BIRTH): an observational study. Lancet Glob Health. 2021;9(3):e267-79. https://doi.org/10.1016/ S2214-109X(20)30504-0.

\section{Publisher's Note}

Springer Nature remains neutral with regard to jurisdictional claims in published maps and institutional affiliations.
Ready to submit your research? Choose BMC and benefit from:

- fast, convenient online submission

- thorough peer review by experienced researchers in your field

- rapid publication on acceptance

- support for research data, including large and complex data types

- gold Open Access which fosters wider collaboration and increased citations

- maximum visibility for your research: over $100 \mathrm{M}$ website views per year

At BMC, research is always in progress.

Learn more biomedcentral.com/submissions 